\title{
Comparison of Shear Bond Strength and Adhesive Remnant Index of Brackets Bonded with Two Types of Orthodontic Adhesives
}

\author{
ELSAAFIN MAHMOUD ${ }^{1}$, MARIANA PACURAR ${ }^{1 *}$, EDWIN SEVER BECHIR ${ }^{1}$, MARIUS MARIS², CRISTIAN OLTEANU³, \\ IONELA TEODORA DASCALU ${ }^{4}$, MARIOARA MOLDOVAN ${ }^{5}$ \\ ${ }^{1}$ Medicine and Pharmacy University of Tirgu Mures, Faculty of Dental Medicine, 38 Gheorghe Marinescu Str., 540142, Tirgu \\ Mures, Romania \\ ${ }^{2}$ Titu Maiorescu University of Bucharest, Faculty of Dental Medicine, 67A Gh. Petrascu Str., 031593, Bucharest, Romania \\ ${ }^{3}$ Iuliu Hatieganu University of Medicine and Pharmacy Cluj Napoca, Faculty of Dental Medicine, 15 Victor Babes Str., 400012, Cluj \\ Napoca, Romania \\ "Medicine and Pharmacy University of Craiova, Faculty of Dental Medicine, 2-4 Petru Rares Str., 200349, Craiova, Romania \\ ${ }^{5}$ Babes Bolyai University of Cluj-Napoca, Department of Polymeric Composites, 1 Mihail Kogalniceanu Str., 400084, Cluj Napoca, \\ Romania
}

\begin{abstract}
The aim of this study was to evaluate shear bond strength and adhesive remnant index between two different brands of adhesive systems and brackets. The adhesive systems were represented by Opal Bond MV Composite and Opal Seal (Ultradent), respectively the fluoride releasing Transbond light cure adhesive paste and Transbond XT (3M). The utilised brackets were Avex metal bracket system (Ultradent), respectively Unitek ${ }^{T M}$ Miniature Twin Metal Brackets (3M). The study was realized on 4 groups of extracted teeth: the first and second groups by using the products of the manufacturer U/tradent, respectively $3 \mathrm{M}$, and the third and fourth groups by using the adhesive system of one manufacturer and the brackets of the other manufacturer. The study revealed that the use of adhesive system and brackets of the same manufacturer may increase the shear bond strength and decrease the adhesive remnant index.
\end{abstract}

Keywords: brackets, seal, shear bond strength, adhesive remnant index

Until the 1960's, orthodontic treatment was done by fabricating bands around all the teeth. The first who described the use of light cured materials in vitro for orthodontic bonding were Tavas and Watts [1] .

Fixed appliance therapy in orthodontics depends on the bonding of brackets to teeth. Adhesive material used in bonding must not be fragile because it causes failure through the ongoing treatment period, which in turn results in time delays and higher costs for the patient. One of the keys of success of the adhesion procedure is based on the fact that it changes the enamel surface because of the acid etching, method developed by Buonocore [2]. When efficient adhesion between orthodontic brackets and the surface of teeth is obtained, which means applying a good bonding system, great results can be obtained from the orthodontic treatment [3]. Direct bonding of orthodontic brackets can be achieved by the micromechanical adhesion of a resin-based material to etched enamel [4]. Several factors play role in affecting the bond strength between the enamel and the brackets [5]. Among these factors are included the type, composition, mode of curing of the adhesive, etching time, concentration of the etchant, bracket material, base design, loading mode and oral environment. The chemical composition of orthodontic bonding adhesives is similar to that of dental composites and sealants [6].

Shear bond strength (SBS) is the main factor, which has to be concerned in the evolution of bonding materials [7].
The shear bond strength of the orthodontic bracket must be able to withstand the forces applied during the orthodontic treatment [8]. For adhesive remnant index (ARI), after debonding we used Artun and Bergland scores $[9,10]$

The adhesives used in our research were Opal Bond MV Composite and Transbond ${ }^{\mathrm{TM}}$ XT Light Cure Adhesive paste (3M Unitek, CA, USA).

Opal ${ }^{\circledR}$ Bond $^{\mathrm{TM}} \mathrm{MV}$ (Ultradent) is a medium viscosity light-cured bonding adhesive for metal and ceramic appliances butters easily into bracket mesh and minimizes drift-upon placement proprietary loading process nearly eliminates run-on. Opal Seal is a 38\% filled primer and sealant that is used to prepare etched enamel to enhance orthodontic bonding and recharge fluoride uptake, helping preventdecalcification. The primer releases and recharges fluoride and is $38 \%$ filled with glass ionomer and nanofillers. The fluorescent properties make reapplication and removal easy and convenient[11]. Transbond XT light cure adhesive (3M) bonds metal and ceramic brackets to tooth surfaces and is available in both syringes and capsules. The viscosity of Transbond XT adhesive was designed to prevent adhesive run-on and bracket skating with the potential to save money and reduce adhesive waste. The product contains acrylate monomers, than the product is not indicated for use with polycarbonate brackets [12]

The ingredients of adhesives used in this study are presented in table 1.

\begin{tabular}{||l|c|}
\hline \multicolumn{1}{|c|}{ Opal seal } & \% by Wt \\
\hline \hline Bis-GMA & $<30^{*}$ \\
\hline HPMA & $<15^{*}$ \\
\hline Ethyl Alcohol & $<10^{*}$ \\
\hline Methacrylic Acid & $<10^{*}$ \\
\hline
\end{tabular}

\begin{tabular}{||l|c||}
\hline \multicolumn{1}{|c|}{ Transbond XT } & $\%$ by Wt \\
\hline \hline Triethylene Glycol Dimethacrylate & $45-55^{*}$ \\
\hline Bisphenol A Diglycidy1 Ether Dimethacrylate & $45-55^{*}$ \\
\hline Triphenylantimony & $<1^{*}$ \\
\hline 4-(Dimethylamino)-Benzeneethanol & $<0.5^{*}$ \\
\hline
\end{tabular}

Table 1

INGREDIENTS OF OPAL SEAL (LEFT) AND TRANSBOND ${ }^{\text {TM }} \mathrm{XT}$ ADHESIVE (RIGHT)

*The specific chemical identity and/or exact percentage (concentration) of this composition has been withheld as a trade secret 
The aim of this study was to evaluate shear bond strength (SBS) and adhesive remnant index (ARI), between the bonding systems and brackets of two manufacturers.

\section{Experimental part}

Materials and Methods

The researches were conducted on 80 extracted human permanent incisors, without caries, restorations, attrition, or fractures, selected for this study. All extracted teeth were stored in normal saline in order to protect the teeth from dehydration, changed weekly to prevent bacteria growth. All selected teeth were polished by fine pumice, for cleaning their enamel surface. The enamel surfaces were etched with $36 \%$ concentration of phosphoric acid (blue etch). The used materials for bonding were Opal adhesive (Opal bond MV composite and Opal seal), Avex brackets, 3M Adhesive (Transbond light cure adhesive paste and Transbond XT) and Unitek TM miniature twin metal brackets. The bonding agent was applied in a uniform thin coat on the enamel surfaces of teeth and on the base of the brackets, by using a special brush. In 40 teeth were used Transbond XT primer and in 40 teeth, Opal seal. The brackets were held in a locking tweezers and the visible light cure system was activated for 10 seconds, for each bracket. Small quantity of the adhesive paste was applied to the base of the brackets, which was seated firmly in the proper position ( $4 \mathrm{~mm}$ away from the occlusal plane, on the buccal surface of teeth) with a steady pressure. The excess of adhesive paste was removed before curing, using sharp probe without disturbing the position. The adhesive bracket/tooth interface was light cured for 20 seconds. The 80 teeth were mounted in cold cure acrylic, as a base, by mixing and pouring into the polypropylene pipe rings and by embedding vertically in the self-cured acrylic resin blocks. The labial surfaces of teeth were positioned at least $2 \mathrm{~mm}$ above the top surface of the acrylic resin after bonding the brackets.

The selected teeth were divided into 4 groups:

- group one, 20 Avex metal brackets were bonded with Opal bond MV and Opal seal on 20 teeth;

- group two, 20 Unitek TM Miniature twin metal brackets were bonded with Transbond XT light cure adhesive past and Transbond XT primer on 20 teeth;

- group three, 20 Avex metal brackets were bonded with Transbond XT light cure adhesive paste and Transbond XT primer on 20 teeth;

- group four, 20Unitek TM miniature twin metal brackets were bonded with Opal bond MV and Opal seal on 20 teeth.

The teeth with brackets were stored in artificial saliva, at $37^{\circ} \mathrm{C}$, for 3 months. The adhesion of brackets to teeth surface was recorded by using shear bond strength (SBS) test, performed by using a universal testing machine (Lloyd Instruments Ltd.). A sharp chisel-type blade was used to apply incisal-cervical loads, to test the shear strength of the ligation. Incisal-cervical task was applied to the adhesive material/bracket interface, with a speed of 1 $\mathrm{mm} / \mathrm{min}$. Shear bond strength values were recorded in Newton (N) and transformed into Megapascal (MPa), by dividing the measured force values at the surface of the bracket, in accordance with the equation: SBS $=F / A(N /$ $\mathrm{mm}^{2}$ or $\mathrm{MPa}$ ), where $F$ is the debonding force in Newtons, and $A$ is the surface area of the bracket base in square millimetres.

After the debonding of brackets, we studied the amount of adhesive remnants, by using a stereo-microscope with 40x magnification. To classify adhesive remnant index (ARI), we used Artun and Bergland scores, classified from 0 to $3(0=$ no adhesive remain on the enamel surface of the tooth; $1=$ less than $50 \%$ of the adhesive remain on the enamel; $2=$ more than $50 \%$ of the adhesive remain on the enamel and less than 100\%; $3=100 \%$ of the adhesive remained on the teeth surface, including bracket mesh impression). For the statistical analysis, the usage of oneway analysis of variance and Tukey's test were used to compare the mean SBS groups, and Krukal-Wallis test was used for comparing the groups of ARI scores.

\section{Results and discussions}

The shear bond strength (SBS) comparisons

In figure 1 are presented the mean SBS values for the four studied groups.

Taking into consideration Tukey's test, as shown in table 2 , differences appeared between the groups: group 1 (10.837 MPa) and group 2 (9.667 MPa), show higher mean of SBS value compared to group 3 (7.109 MPa) and group 4 (7.045 MPa).

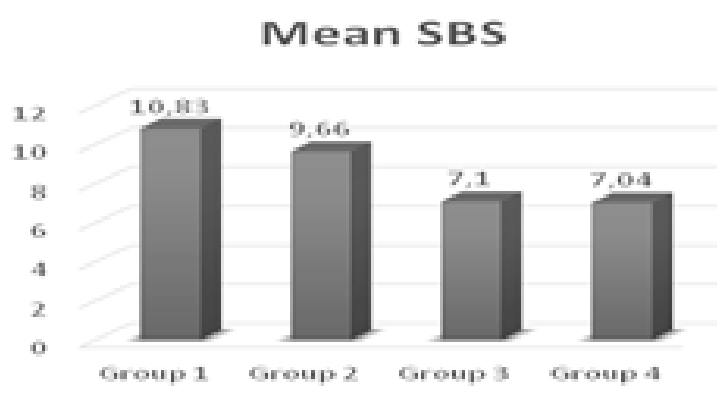

Fig. 1. Obtained mean shear bond strength values

This study showed the mean SBS of group 1 (Avex metal brackets, Opal bond MV and Opal seal) was (10.837 $\mathrm{MPa}$ ), the highest of all groups, and this resultcorresponded with other studies that said the fluoride in bonding material gave adequate shear bond strength.

In this study the statistical analysis of the shear bond strength showed that there was no statistical difference between group 1 (Avex metal brackets, Opal bond MV and Opal seal) and group 2 (Unitek TM twin metal brackets, Transbond XT adhesive and Transbond XT primer). Group 2 (Unitek TM twin metal brackets, Transbond XT adhesive and Transbond XT primer) was on the second place (9.667MPa), with very small difference in comparison with group 1. Both groups 1 and 2 showed high mean SBS, because both used the same manufacturer of brackets and bonding system. When the brackets and bonding systems from different manufacturers were used, the mean SBS decreased, which was seen in group 3 (Avex metal brackets, Transbond XT light cure adhesive paste and Transbond XT primer) and group 4 (Unitek TM miniature twin metal brackets, Opal bond MV and Opal seal).

Statistical analysis showed that there were significant differences between groupl and group 2 as compared to group 3 and group 4 in mean of SBS comparison. The mean SBS of group 3 and group 4 were (7.109MPa) and (7.045 $\mathrm{MPa}$ ).

Table 2

$p$ VALUES OF TUKEY TEST FOR SBS IN GROUPS

\begin{tabular}{||l||c|c|c|c||}
\hline & Group 1 & Group 2 & Group 3 & Group 4 \\
\hline \hline Group 1 & & 0.492 & 0.025 & 0.042 \\
\hline Group 2 & 0.492 & & 0.016 & 0.05 \\
\hline Group 3 & 0.042 & 0.05 & & 0.14 \\
\hline Group 4 & 0.025 & 0.016 & 0.14 & \\
\hline
\end{tabular}




\begin{tabular}{||l||c|c|c|c||c||}
\hline \hline $\begin{array}{c}\text { no adhesive } \\
\text { = score 0 }\end{array}$ & $\begin{array}{c}<\mathbf{5 0 \%} \\
\text { adhesive } \\
\text { = score 1 }\end{array}$ & $\begin{array}{c}\mathbf{> 5 0 \%} \\
\text { adhesive } \\
\text { = score 2 }\end{array}$ & $\begin{array}{c}\mathbf{1 0 0 \%} \\
\text { adhesive } \\
\text { score 3 }\end{array}$ & $\begin{array}{c}\text { Mean } \\
\text { post }\end{array}$ \\
\hline \hline Group 1 & 6 & 9 & 3 & 2 & 28.28 \\
\hline Group 2 & 7 & 8 & 4 & 1 & 26.28 \\
\hline Group 3 & 0 & 5 & 6 & 9 & 53.08 \\
\hline Group 4 & 0 & 3 & 9 & 8 & 54.38 \\
\hline
\end{tabular}

Table 3

SCORES OF ADHESIVE REMNANT INDEX (ARI) AND MEAN POST OF ARI

\section{Adhesive remnant index (ARI) comparisons}

The descriptive statistic for the ARI scores between all four groups shows that there was a significant difference $(p=0.001)$.

Table 3 shows that the mean rank of ARI scores obtained in group 1 (26.28) and group 2 (28.28), in group 3 (54.38) and in group 4 (35.08), mean post ARI scores.

Adhesive remnant index study shows that there were significant differences between all groups, value $=0.001$. Group 1 and group 2 showed lower quantity of ARI than group 3 and group 4, because the adhesive between the brackets and composite were stronger in the first and second group than in the others, taking into consideration that group 1 and group 2 used brackets and adhesive from the same manufacturer.

This study showed the fact that when the SBS increased, the quantity of ARI on the tooth decreased.

The first dental product used in this study was the Opal adhesive (opal bond MV and opal seal) with the properties of releasing and recharging fluoride, $38 \%$ filled with glass ionomer fillers plus nanofillers, for long lasting strength. It was noticed that this type of adhesive with fluoride containing, increases the enamel strength by facilitating its remineralisation [13,14], at the same time, increasing the shear bond strength and facilitates the ease removal of residual material [15]. The second studied product was Transbond XT lightcure adhesive, which does not discolour the enamel rather it creates a contrast to the chalky appearance of the surrounding enamel. Transbond XT composite present good adhesion to enamel and that is why it is used widely in orthodontic practice and studies as control $[16,17,18]$.

Brackets had influence on SBS through the surface of bracket in contact with the tooth and through the number of mashes built in the bracket. In this study 2 different types of brackets were used (Avex bracket and Unitek TM miniature twin metal bracket). Different studies and articles were done for minimum SBS and by taking the mean average it was decided to be in between $5.88 \mathrm{MPa}$ and $7.84 \mathrm{MPa}[19,20]$. Reynolds et al [21] stated that 5.9$7.8 \mathrm{MPa}$ resistances are sufficient to withstand masticatory forces. Bishara et al [22] compared bond strengths of an acidic primer and composite resin with a conventional adhesive system and found mean bond strengths of 10.4 and $11.8 \mathrm{MPa}$, respectively. The SBSs of self-etching primers can vary widely, ranging from 2.8 to $16.6 \mathrm{MPa}$ [14]. Several studies did show that brackets can cause enamel loss during debonding, specifically when the fracture happens at the enamel-adhesive interface. Damaging of the enamel can occur in the form of cracks, which may propagate during debonding. Enamel cracks may add more risks on the integrity of the enamel and other esthetic problems to the patient $[23,24]$. At the same time, when the SBS increased, the quantity of ARI on the tooth decreased, but this value was contradictory with other research that said the SBS value did not correspond to the
ARI $[25,26]$. During orthodontic treatment, the usage of brackets adhesion transmits a specific force to the teeth, which is important to give positive results at the end of treatment. The increase of bonding strength of brackets leads to decrease in the percentage of bracket debonding, has in turn the advantage of saving time and preserves a healthy enamel surface $[27,28]$. The success of any fixedappliance orthodontic treatment depends on multiple factors, most important of which being correct bracket placement and bonding together with the longevity of these accessories on the teeth. In vitro study of Mesaros et al [29], demonstrated that the majority of fractures appeared at the tooth-adhesive interface. Dental bleaching generates changes in the enamel surface chemistry, with a negative influence on the adhesion. After the researches of Moldovan et al [30] and Rominu etal [31], the reduction of SBS values could be explained by the high residual oxygen that is released from the bleaching agent and which can interfere with the infiltration of resin into the etched enamel. The study of Szuhanek et al [32] shows that the mechanical treatment creates a very fine roughness on the surface area, and increases mechanical and chemical bonding between the tooth surface and the bracket base. After Mirzakouchaki et al [33], the bonding materials should penetrate into the enamel porosities and have simple manipulation and dimensional stability, butZanarini etal [34] consider that the material should also not damage the enamel at the end of the treatment when debonding takes place.

A good bonding system is literally the most important way to ensure the good adhesion of orthodontic pieces, because loose brackets during treatment mean increasing costs for both the patient and the dentist [35]. A large number of studies were published regarding the materials for adhesion, but it has not been possible to reach a consensus about the product that represents the gold standards [36].

\section{Conclusions}

The bonding system utilized with florid may increase the bond strength.

Using the adhesive and bracket from the same manufacturer may increase SBS and decrease the quantity of ARI.

The use of adhesive and bracket from different manufacturers may decrease SBS and increase quantity of ARI.

ARI quantity is inversely proportional with SBS.

\section{References}

1.TAVAS MA, WATTS DC, Br J Orthod. 1979;6:207-8

2. BUONOCORE MG, J Dent Res, 1955;34:849-53

3.de MENDONÇA INVERNICI S, MARUO IT, CAMARGO ES, HIRATA TM, MARUO H, FILHO GO, TANAKA O, Dental Press Journal of Orthodontics, 2012, 17(3), 31-39

4.ARNOLD RW, COMBE EC, WARFORD JH J r., Am J Orthod Dentofac Orthop. 2002;122:274-6 
5.ANSARI MY, AGARWAL DK, GUPTA A, BHATTACHARYA P, ANSAR J, BHANDARI R, Journal of Clinical and Diagnostic Research: JCDR. 2016;10(11):ZC64-ZC68

6.RAHIOTIS C, Semin Orthod. 2010;16(4):266-73

7.SHARMA S, TANDON P, NAGAR A, SINGH GP, SINGH A, CHUGH VK, Journal of Orthodontic Science, 2014;3(2):29-33

8.ASHTEKAR S, SHETTY P, DESHPANDE R, JADHAV P, J Indian Orthod SOC, 2016;50:240-5

9.MONTASSER MA, DRUMMOND JL, Angle Orthod, 2009;79:773-776

10.FOERSCH M, SCHUSTER C, RAHIMI RK, WEHRBEIN H, JACOBS C, Angle Orthod, 2016, 86:2, 260-264

11.*** http://www.opalorthodontics.com/products/adhesives/primersand-sealants/opal-seal-fluoride-releasing-and-recharging-primer-andsealant/Pages/default.aspx\#productInformation

12.*** http://www.3m.com/3M/en_US/company-us/all-3m-products/ / Transbond-XT-Light-Cure-Adhesive?N=5002385+8710666+ 8716971+3293080886\& $\mathrm{rt}=$ rud

13.BISHARA SE, SOLIMAN M, LAFFOON J, WARREN J , Angle Orthod. 2005;75(3):397-9

14.CACCIAFESTA V, SFONDRINI MF, CALVI D, SCRIBANTE A, Am J OrthodDentofacialOrthop. 2005;127(5):580-3

15.ROMANO FL, CORRER AB, SOBRINHO LC, BORGES DE ARAÚJOMAGNANI MD, VIEIRA DE SIQUEIRA VC, Braz J Oral Sci, 2009;8,2:76-80

16.SFONDRINI MF, CACCIAFESTA V, SCRIBANTE A, DE ANGELIS M, KLERSY C, Am J OrthodDentofacialOrthop. 2004;125:357-60

17.GRUBISA HIS, HEO G, RABOUD D, GLOVER KE, MAJOR PW, Am J OrthodDentofacialOrthop. 2004;126:213-9

18.ROMANO FL, TAVARES SW, CONSANI S, MAGNANI MBBA, NOUER DF, Angle Orthod. 2005;75:849-53

19. REYNOLDSIR, VON FRAUNHOFER JA, BrJ Orthod. 1977;4(2):65-9. 20.GIANNINI C, FRANCISCONI PAS, Dental Press OrtodonOrtop Facial. 2008;13(3):50-9

21.REYNOLDS IR, Br J Orthod. 1975;2:171-8

22.BISHARA SE, GORDAN VV, VONWALD L, OLSON ME, Am J Orthod Dentofacial Orthop. 1998;114:243-7
23.TOLEDANO M, OSORIO R, OSORIO E, ROMEO A, DE LA HIGUERA B, GARCIA-GODOY F, Angle Orthod. 2003 Feb;73(1):56-63

24.ZACHRISSON BU, SKOGAN 0, HOYMYHR S, Am J Orthod. 1980;77(3):307-19

25.DORMINEY JC, DUNN WJ, TALOUMIS LJ, Am J OrthodDentofacialOrthop. 2003;124:410-3

26.RODRIGUEZ GCD, CARVALHO PAL, HORLIANA RF, BOMFIM RA, Ortodontia. 2002 Abr-J un;53(2):28-34

27.SHINYA M, SHINYA A, LASSILA LV, GOMI H, VARRELA J, VALLITTU

PK, Dent Mater J. 2008;27(1):1-6

28.UYSAL, T, USTDAL, A, KURT, G, Eur J Orthod. 2010;32(2):214-8

29.MESAROS, A, ALB, C , CULIC, B, MESAROS, M , MOLDOVAN, M , BRU CIFRE, L, BADEA, M, Rev. Chim. (Bucharest), 66, no. 1, 2015, p. 66

30.MOLDOVAN, M., ALMASI, A., PREJ MEREAN, C., MUSAT O., SILAGHI DUMITRESCU, L., NICOLA, C., COJ OCARU, I., PASTRAV O., Mat. Plast., 46, no. 4, 2009, p. 404

31.ROMINU, R.O, NEGRUTIU, M., RUSU, LC, ARDELEAN, L, TUDOR, A., ROMINU, M, Rev Chim. (Bucharest), 63, no. 3, 2012, p. 265

32.SZUHANEK, C., JIANU, R., COCORA, R.O, NEGRUTIU, M.L, SINESCU, C., CLONDA, C.S, SCHILLER, E., GRIGORE, A., POPA, A., Rev. Chim.(Bucharest), 67, no. 12, 2016, p. 2605

33.MIRZAKOUCHAKI B, SHIRAZI S, SHARGHI R, SHIRAZI S, MOGHIMI $M$, SHAHRBAF S, Journal of Clinical and Experimental Dentistry. 2016:8(1):e38-e43

34.ZANARINI M, GRACCO A, LATTUCA M, MARCHIONNI S, GATTO MR, ALESSANDRI BONETTI GA, Angle Orthodontist, 2013, Vol 83, No 5, 885-891

35.DE MENDONCA INVERNICI S, TOSHIO IV, CAMARGO ES, MIYUKI HT, HIROSH MI, ODILON GF, TANAKA O, Dental Press J. Orthod. [Internet]. 2012; 17(3): 31-39

36. BECHIR, A, BECHIR, ES, MANU, R, BURCEA, A, GIOGA, C, BARBU, H.M., BIRIS, C, CIAVOI, G, DASCALU, IT, Rev. Mat. Plast., 53, no. 4, 2016, p. 661

Manuscript received: 3.12 .2106 